\title{
Prevalence and management of hypertension in primary care practices with electronic medical records: a report from the Canadian Primary Care Sentinel Surveillance Network
}

\author{
Marshall Godwin MD MSc, Tyler Williamson PhD, Shahriar Khan MSc, Janusz Kaczorowski PhD, \\ Shabnam Asghari PhD, Rachel Morkem MSc, Martin Dawes MD, Richard Birtwhistle MD MSc
}

\section{Abstract}

Background: Most epidemiologic reports on hypertension in Canada are based on data from surveys or on administrative data. We report on the prevalence and management of hypertension based on data from the Canadian Primary Care Sentinel Surveillance Network (CPCSSN), which consists of validated, national, point-of-care data from primary care practices.

Methods: We included CPCSSN data as of Dec. 31, 2012, for patients 18 years and older who had at least 1 clinical encounter during the previous 2 years with one of the 444 family physicians and nurse-practitioners who participate in the CPCSSN. We calculated the prevalence of hypertension, the proportion of patients who achieved blood pressure targets, the number of encounters with primary care providers, comorbidities and pharmacologic management.

Results: Of the 250346 patients who met the eligibility criteria, $57180(22.8 \%)$ had a diagnosis of hypertension. Of the 44981 patients for whom blood pressure data were available, $35094(78.0 \%)$ had achieved both targets for systolic $(\leq 140 \mathrm{~mm} \mathrm{Hg})$ and diastolic ( $\leq 90 \mathrm{~mm} \mathrm{Hg}$ ) pressure. Compared with patients who did not have a hypertension diagnosis, those with hypertension were significantly more likely to have a comorbidity and visited their primary care provider more often. Among the patients with hypertension, $12.1 \%$ were not taking antihypertensive medications; nearly two-thirds (61.7\%) had their condition controlled with 1 or 2 drugs.

Interpretation: The prevalence of hypertension based on CPCSSN data was similar to estimates from the Canadian Health Measures Survey. Although achievement of blood pressure targets was high, patients with hypertension had more comorbidities and saw their primary care provider more often than those without hypertension.

\begin{abstract}
A ccording to the Global Burden of Disease Study, ${ }^{1}$ high blood pressure is the greatest risk factor for ill health and early death worldwide. ${ }^{2-4}$ The Canadian Health Measures Survey, conducted between March 2009 and February 2011, measured blood pressure directly using an automated device. The survey showed that an estimated 1 in 5 Canadian adults have hypertension and another 20\% have blood pressure in the prehypertensive range. ${ }^{5}$ Of the respondents with hypertension, $83 \%$ were aware they had high blood pressure, and $80 \%$ were receiving treatment for it; $66 \%$ had achieved recommended target levels. The lifetime residual risk of hypertension among people aged 55-65 years with normal blood pressure is estimated to be $90 \%,{ }^{6}$ which makes high blood pressure a concern for virtually everyone. Cardiovascular diseases have the highest financial health care cost of all diseases ${ }^{7}$ and are responsible for the greatest number of visits to family physicians in Canada - more than 20 million visits annually. ${ }^{8}$ In Canada, the cost of hypertension-related
\end{abstract}

physician visits, laboratory tests and medications were estimated in 2007 to be almost $\$ 2.4$ billion. $^{9}$

Most people with hypertension in Canada are managed in the primary care setting by family physicians and other members of the primary care team. It is in this setting that routine diagnosis and treatment are ideally studied. Data on the prevalence and management of chronic disease in Canada and most other countries usually come from cross-sectional national or

Competing interests: Janusz Kaczorowski received a research grant and consulting fees from Servier Canada. No other competing interests were declared.

This article has been peer reviewed.

Correspondence to: Marshall Godwin, godwinm@mun.ca

CMAJ Open 2015. DOI:10.9778/cmajo.20140038 
provincial surveys or from administrative data. Surveys are prone to selection, reporting and recall bias. Administrative billing data have a number of limitations, including the requirement for only 1 diagnosis, the lack of contextual or background information, and the restriction of collected information to data required for administrative purposes. These sources do not provide the same level of detail as data from the Canadian Primary Care Sentinel Surveillance Network (CPCSSN) database, especially those related to information on point-of-care management, achievement of targets, and other risk factors and comorbidities.

The purpose of the report is to provide information from the CPCSSN to the health care community (practitioners, researchers and policy-makers) on the current state of hypertension prevalence, comorbidities, management and achievement of recommended targets - in primary care.

\section{Methods}

\section{Physician recruitment and study population}

The CPCSSN is a network of practice-based research networks established in 2008 with ongoing recruitment. Each practice-based research network, mostly based in university departments of family practice, was invited to recruit family physicians and nurse-practitioners who use electronic medical records (EMRs) in their practice. The recruitment process initially (2008-2010) included practices associated with academic teaching sites. It has since broadened to include practices from inner-city, urban, suburban, small town and rural areas. The director of each local research network actively recruits practices with an attempt to balance practice location and type. Inclusion of practices is not random owing to the need for the practice to use EMRs, practitioners' willingness to participate, and the logistics of geography and funding. Table 1 describes the practices participating in the CPCSSN.

The study population comprised all patients 18 years and older who had at least 1 clinical encounter at a participating practice in the 2 years before the study.

\section{Data collection}

The CPCSSN ${ }^{9,10}$ currently collects information from more than 500 participating primary care providers (sentinels) across Canada that provide data from EMRs on more than 600000 patients from their practices. To date, the CPCSSN has developed and validated algorithms for the identification of a number of chronic conditions in primary care: hypertension, diabetes, depression, osteoarthritis, chronic obstructive pulmonary disease (COPD), dementia, Parkinsonism and epilepsy. ${ }^{11,12}$ Every 3 months, de-identified data are extracted from the EMRs, cleaned, coded and transformed into a common data format for inclusion in the secure CPCSSN database. The network's data extraction process, specifically the de-identification, storage and use of EMR data, has been reviewed and approved by 10 university research ethics boards across Canada and by the Health Canada Research Ethics Board.

For our study, we used patient data extracted on Dec. 31, 2012, at which time 444 physicians contributed data on about
440000 patients. We included information on blood pressure levels, demographic characteristics, the 7 comorbid conditions other than hypertension for which the CPCSSN has a case-identifying algorithm, the drugs and other strategies used to manage the hypertension, and the outcomes associated with treatment.

The case-finding algorithm we used to determine the presence of hypertension is based on combinations of diagnostic billing data, the table of health conditions in the EMR and use of antihypertensive medications. The algorithm has been validated and has a sensitivity of $84.9 \%$, specificity of $93.5 \%$ and positive predictive value of $92.9 \%{ }^{11,12}$

\section{Definitions}

To determine whether a patient had achieved their target blood pressure, we used the average of the last 3 measurements (or whatever was available) taken in the 2 years before the study. Of the 57180 patients with hypertension, $12199 \mathrm{did}$ not have a blood pressure measurement recorded on the chart in that period; of the 44981 who did, the determination of whether they had achieved the target was based on a single reading for $4822(10.7 \%)$ people, the average of 2 measurements for $5557(12.4 \%)$ people and the average of 3 measurements for 34602 (76.9\%) people.

For this report, we considered a medication to have been used if there was at least 1 prescription for that medication recorded in the patient's EMR. Most (95\%) of these prescriptions were last recorded within the 2 years before the study. We have no effective way of determining if the medications were actually taken as prescribed.

We defined location as rural if the second character in the postal code was 0 , in keeping with Canada Post's designation, ${ }^{13}$ and urban if the character was greater than zero. Rural areas are those where there is no door-to-door mail delivery and people pick up their mail at a general mailbox or post office, or where rural route drivers deliver the mail because of the distance from a postal outlet. The designation is highly specific for rural location but not as sensitive because some low-population locations do have door-to-door delivery and have a number greater than zero as the second character in the postal code. The postal code designation of rural does not have a specific population designation but generally represent areas with fewer than 10000 people.

\section{Statistical analysis}

We performed a combination of descriptive statistics and multivariable analysis using the statistical software package SAS, version 9.3 (SAS Institute). We estimated the prevalence of hypertension by age group and sex. We then calculated ageand sex-standardized rates using Canadian population data for $2011 .^{14}$ In the multivariable analysis, we used the log link function of binomial distribution for dichotomous outcomes (e.g., presence or absence of hypertension) and of Poisson distribution for count data (e.g., number of comorbid conditions) by applying the GENMOD procedure in SAS. We estimated prevalence ratios for 3 variables: location (rural or urban), body mass index (BMI) categories (underweight: $\mathrm{BMI}<18$, normal: $18 \leq \mathrm{BMI}<25$, overweight: $25 \leq \mathrm{BMI}<30$ and obese $\geq 30$ ) and smoking status (never, past or current). Because the presence of 


\section{OPEN}

Research

interactions can have important implications for the interpretations of our regression results, we included 8 interaction terms in our model to control for their effects on the prevalence ratio. The interaction terms were age by sex, age by BMI, age by smoking status, sex by BMI, sex by smoking, location by BMI, location by smoking and BMI by smoking.

We performed a log link function of Poisson regression on the 7 comorbid conditions identified with the CPCSSN algorithms, using age and sex as control variables. Subsequent to this, we performed a multivariable analysis on utilization data, taking age, sex, location and comorbid conditions into account as control variables and using the log link function of Poisson distribution. We estimated the prevalence of each comorbid condition, adjusting for age and sex, among patients with and without hypertension, using the same log-binomial approach. The cumulative proportion of patients with 1 or more of the 7 comorbid conditions other than hypertension was estimated and the average number of comorbid conditions calculated by age group. The variation in prescriptions of antihypertensive medications among patients with hypertension was described.

\section{Results}

We extracted data on 250346 patients, of whom 57180 $(22.8 \%)$ had a diagnosis of hypertension. The age-standardized prevalence of hypertension was 20.4\%. Table 2 provides baseline data on the cohort. Patients with a diagnosis of hypertension differed significantly from those without hypertension in all of the variables. This was probably due to the large sample size. Many of the differences were not large enough in magnitude to have much clinical importance, except for age, number of comorbid conditions and number of encounters with the primary care provider. People with hypertension had a mean of 11.2 encounters with their primary care provider in the 2-year period, as compared with 6.6 encounters among those without hypertension. After we controlled for other factors using multivariable analysis, we found that patients with hypertension still had about $30 \%$ more encounters than those without hypertension.

Figure 1 shows the prevalence of hypertension by sex and how it changed with increasing age. After age 70, hypertension was more prevalent among women than among men.

The prevalence of hypertension was higher in rural than in urban locations, it increased with increasing BMI, and it was higher among past smokers than among patients who had never smoked (Table 3). Because of the large amount of missing data, especially for BMI and smoking status, we included, as a group, people with missing data in each variable when calculating prevalence ratios. For the variables location and BMI, the missing-data group did not differ significantly from

Table 1: Characteristics of the regional networks and sentinel primary care practices participating in the Canadian Primary Care Sentinel Surveillance Network as of Dec. 31, 2012

\begin{tabular}{|c|c|c|c|c|c|}
\hline \multirow[b]{2}{*}{ Regional network } & \multirow[b]{2}{*}{ Province } & \multirow{2}{*}{$\begin{array}{l}\text { City, university } \\
\text { affiliation }\end{array}$} & \multicolumn{2}{|c|}{$\begin{array}{l}\text { No. of sentinel } \\
\text { practices }\end{array}$} & \multirow{2}{*}{$\begin{array}{l}\text { No. of patients } \\
\text { overall* }\end{array}$} \\
\hline & & & Total & Rural & \\
\hline $\begin{array}{l}\text { British Columbia Primary Care Research } \\
\text { Network (BCPCReN) }\end{array}$ & British Columbia & $\begin{array}{l}\text { Vancouver, University } \\
\text { of British Columbia }\end{array}$ & 13 & 0 & 8744 \\
\hline $\begin{array}{l}\text { Alberta Family Practice Research Network } \\
\text { (AFPRN) }\end{array}$ & Alberta & $\begin{array}{l}\text { Edmonton, University } \\
\text { of Alberta }\end{array}$ & 35 & 0 & 15211 \\
\hline $\begin{array}{l}\text { Southern Alberta Primary Care Research } \\
\text { Network (SAPCReN) }\end{array}$ & Alberta & $\begin{array}{l}\text { Calgary, University } \\
\text { of Calgary }\end{array}$ & 52 & 16 & 32000 \\
\hline $\begin{array}{l}\text { Manitoba Primary Care Research Network } \\
\text { (MaPCReN) }\end{array}$ & Manitoba & $\begin{array}{l}\text { Winnipeg, University } \\
\text { of Manitoba }\end{array}$ & 32 & 4 & 27618 \\
\hline $\begin{array}{l}\text { Deliver Primary Healthcare Information } \\
\text { Project (DELPHI) }\end{array}$ & Ontario & $\begin{array}{l}\text { London, Western } \\
\text { University }\end{array}$ & 21 & 5 & 16995 \\
\hline $\begin{array}{l}\text { University of Toronto Practice Based } \\
\text { Research Network (UTOPIAN) }\end{array}$ & Ontario & $\begin{array}{l}\text { Toronto, University } \\
\text { of Toronto }\end{array}$ & 130 & 0 & 61264 \\
\hline Eastern Ontario Network (EON) & Ontario & $\begin{array}{l}\text { Kingston, Queen's } \\
\text { University }\end{array}$ & 46 & 14 & 26011 \\
\hline $\begin{array}{l}\text { Primary Care Research Network of the } \\
\text { University of Montréal (PCRNUM) }\end{array}$ & Quebec & $\begin{array}{l}\text { Montréal, University } \\
\text { of Montréal }\end{array}$ & 25 & 0 & 4961 \\
\hline $\begin{array}{l}\text { Maritime Family Practice Research Network } \\
\text { (MARNET-FP) }\end{array}$ & Nova Scotia & $\begin{array}{l}\text { Halifax, Dalhousie } \\
\text { University }\end{array}$ & 43 & 19 & 33811 \\
\hline $\begin{array}{l}\text { Atlantic Practice Based Research Network } \\
\text { (APBRN) }\end{array}$ & $\begin{array}{l}\text { Newfoundland } \\
\text { and Labrador }\end{array}$ & $\begin{array}{l}\text { St. John's, Memorial } \\
\text { University of } \\
\text { Newfoundland }\end{array}$ & 47 & 2 & 23631 \\
\hline
\end{tabular}


the reference category. For smoking status, the missing-data group was significantly different from the reference category of never smoked, which suggests that the smoking results should be interpreted with caution.

Of the patients with hypertension for whom data on blood pressure measurements were available $(n=44981), 35094$ (78.0\%) had achieved both the systolic target $(\leq 140 \mathrm{~mm} \mathrm{Hg})$ and the diastolic target $(\leq 90 \mathrm{~mm} \mathrm{Hg}$ ) (Table 4). Among those with hypertension and diabetes for whom data were available $(n=9782), 4434(45.3 \%)$ had achieved both targets (systolic $\leq 130 \mathrm{~mm} \mathrm{Hg}$; diastolic $\leq 80 \mathrm{~mm} \mathrm{Hg}$ ).

People with hypertension were significantly more likely to have a diagnosis of diabetes, COPD, osteoarthritis and depression than people without hypertension (Table 5). The number of comorbid conditions increased markedly with age (Figure 2), and those with hypertension had more comorbid conditions throughout the age range. Overall, people with hypertension were 1.34 times as likely to have other chronic conditions as patients without hypertension. However, even among patients with hypertension, $80 \%$ had either no or only 1 comorbid condition.

Figure 3 provides a breakdown of the prescriptions by type of antihypertensive medication among the patients with hypertension. Eighty-eight percent of patients with hypertension were prescribed an antihypertensive medication; the most commonly prescribed were angiotensin-converting-enzyme

Table 2: Characteristics of the study population*

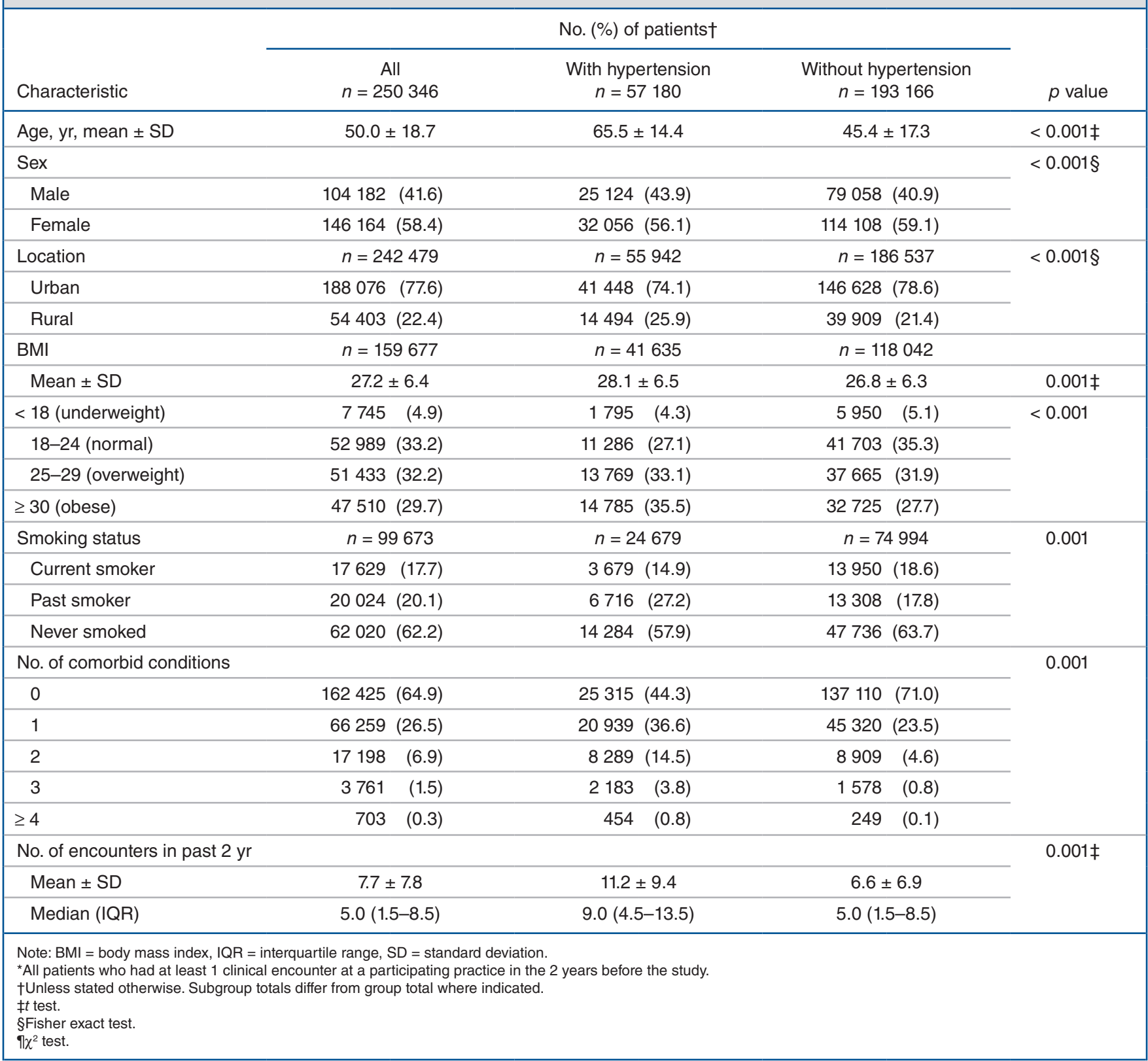




\section{OPEN}

Research

inhibitors and thiazide diuretics. Nearly two-thirds (61.7\%) of those prescribed an antihypertensive medication were prescribed 1 or 2 drugs (Figure 4).

\section{Interpretation}

Overall, 22.8\% of adult patients in CPCSSN participating practices had a diagnosis of hypertension. The prevalence was highest in rural areas and among people who were overweight

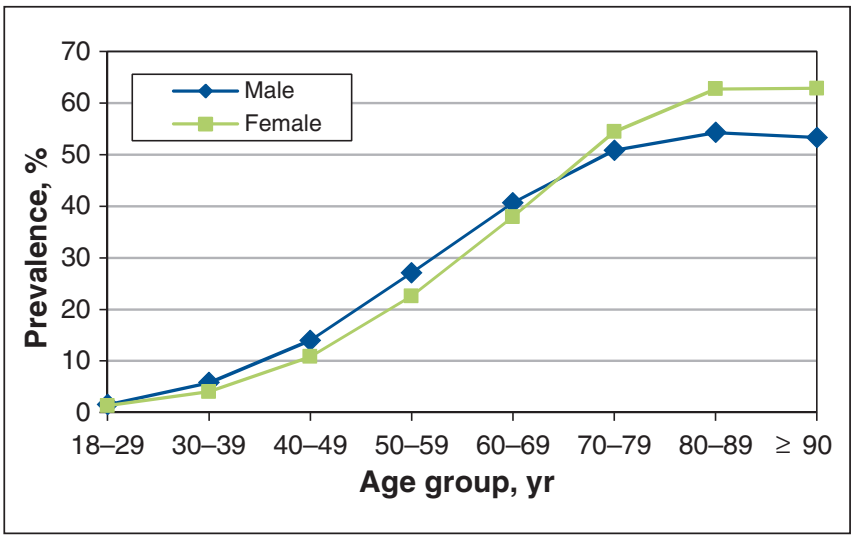

Figure 1: Prevalence of hypertension by age and sex among patients in sentinel primary care practices participating in the Canadian Primary Care Sentinel Surveillance Network. or obese. Although achievement of blood pressure targets was high $(80 \%)$, patients with hypertension had more comorbidities and saw their primary care provider more often than those without hypertension. Nearly half of those with both hypertension and diabetes had achieved the lower recommended blood pressure targets. Most patients with hypertension were able to control the condition with 1 or 2 antihypertensive medications.

The estimated prevalence of hypertension in the CPCSSN practices is less than $1 \%$ higher than the $22 \%$ reported by the Canada Health Measurements Survey conducted between 2009 and 2011.5 Prevalence based on a clinical population should be higher than a population-based estimate, because a practice-based population would be expected to have higher rates of morbidity. However, because it has been estimated that nearly $85 \%$ of Canadians aged 12 and over have a regular family physician, ${ }^{15}$ this difference should not be great. CPCSSN data are updated every 3 months, so the prevalence can be monitored regularly without the cost of large-scale population-based surveys.

\section{Limitations}

There are limitations to the use of EMR data in research. The data are collected for clinical purposes, not research. We would like to have had better data regarding socioeconomic

Table 3: Prevalence ratios for hypertension, by location, BMI and smoking status*

\begin{tabular}{|c|c|c|c|c|c|}
\hline \multirow[b]{2}{*}{ Variable } & \multicolumn{3}{|c|}{ No. of patients } & \multirow[b]{2}{*}{$\begin{array}{l}\text { Unadjusted } \\
\text { prevalence ratio }\end{array}$} & \multirow[b]{2}{*}{$\begin{array}{c}\text { Adjusted prevalence } \\
\text { ratio† }(95 \% \mathrm{Cl})\end{array}$} \\
\hline & All & With hypertension & $\begin{array}{c}\text { Without } \\
\text { hypertension }\end{array}$ & & \\
\hline \multicolumn{6}{|l|}{ Location } \\
\hline Urban & 188076 & 42448 & 146628 & 1.00 & 1.00 (ref) \\
\hline Rural & 54403 & 14494 & 39909 & 1.21 & $1.24(1.19-1.30)$ \\
\hline Missing data & 7867 & 1238 & 6629 & 0.71 & $0.95(0.82-1.11)$ \\
\hline \multicolumn{6}{|l|}{ BMI } \\
\hline 18-24 (normal) & 52989 & 11286 & 41703 & 1.00 & 1.00 (ref) \\
\hline < 18 (underweight) & 7745 & 1795 & 5950 & 1.09 & $1.13(0.95-1.35)$ \\
\hline 25-29 (overweight) & 51433 & 13769 & 37664 & 1.26 & $1.51(1.38-1.64)$ \\
\hline$\geq 30$ (obese) & 47510 & 14785 & 32725 & 1.46 & $2.42(2.22-2.63)$ \\
\hline Missing data & 90669 & 15545 & 75124 & 0.81 & $0.99(0.91-1.08)$ \\
\hline \multicolumn{6}{|l|}{ Smoking status } \\
\hline Never smoked & 62020 & 14284 & 47736 & 1.00 & 1.00 (ref) \\
\hline Current smoker & 17629 & 3679 & 13308 & 0.91 & $1.01(0.89-1.15)$ \\
\hline Past smoker & 20024 & 6716 & 13308 & 1.46 & $1.94(1.73-2.16)$ \\
\hline Missing data & 150673 & 32501 & 118172 & 0.94 & $1.50(1.40-1.61)$ \\
\hline $\begin{array}{l}\text { Note: } \mathrm{Cl}=\text { confidence inter } \\
\text { *Missing data included as } \\
\text { data included as a group in } \\
\text { †Log-binomial regression. } \\
\text { sex*BMI, age* smoking, sex }\end{array}$ & $\begin{array}{l}\text { ference cat } \\
\text { he models. } \\
\text { able when ce } \\
5 \text { main effec } \\
\text { location*BN }\end{array}$ & $\begin{array}{l}\text { f the large amount of } \mathrm{mi} \\
\text { revalence ratios. } \\
\text { (age, sex, location, BM } \\
{ }^{*} \text { smoking, and BMI }{ }^{*} \text { smo }\end{array}$ & $\begin{array}{l}\text { ta, especially for } \\
\text { hoking status), the } \\
\text { hly the effects of lo }\end{array}$ & $\begin{array}{l}\text { moking status, we inc } \\
\text { so included } 8 \text { interacti } \\
\text { MI and smoking status }\end{array}$ & $\begin{array}{l}\text { d people with missing } \\
\text { rms: age*sex, age*BMI, } \\
\text { reported in this table. }\end{array}$ \\
\hline
\end{tabular}


factors such as income, education and ethnicity, but they are rarely collected in a clinical setting. Weight is reasonably well documented, but height is less frequently measured, and hence BMI cannot always be calculated. Waist circumference is rarely documented. We were able to calculate BMI for only $64 \%$ of the patients, and smoking status was recorded for only $40 \%$ of patients. Some of the sentinel practices have laboratory interfaces incorporated into their EMRs so that laboratory results and diagnostic imaging data are loaded directly into their database. Others have the paper reports scanned as PDFs into their system; the data on these files cannot be accessed for research or surveillance. Some physicians record blood pressure, weight and other such measurements in the text-based progress notes rather than in the fields designed for these measures. It is difficult to extract these data with any degree of accuracy. We are working with our sentinel physicians to encourage more accurate, complete and useful recording, but change takes time.

The technique of blood pressure measurement likely varied among the practitioners, such as whether the patient was rested before the measurement, whether the arm was at the correct position, whether the correct cuff size was used, whether the physician or the nurse measured the blood pressure and whether a manual or automatic measurement device was used. In addition, the interval between blood pressure measurements varied between patients, as did the number of measurements (1, 2 or 3 ) we used to calculated the mean blood pressure. Our assessment of related comorbidities was also limited because we have not yet developed case-finding algorithms to identify conditions such as heart disease and renal disease.

Another issue is generalizability. A substantial number of physicians and their practices have been recruited to the CPCSSN. However, inclusion of practices is not random, and the proportion of physicians with academic practices is larger in the CPCSSN than in the general population of physicians. We are beginning to look at the demographics of our sentinel physicians and their practices and recruit more strategically.

Table 4: Achievement of blood pressure targets*

\begin{tabular}{|cc|}
\hline Patient group; target pressure, $\mathrm{mm} \mathrm{Hg}$ & $\begin{array}{c}\text { No. (\%) } \\
\text { of patients }\end{array}$ \\
\hline With hypertension & $n=44981 \dagger$ \\
\hline Systolic $<140$ & $35904(79.8)$ \\
\hline Diastolic $<90$ & $42521(94.5)$ \\
\hline Both systolic $<140$ and diastolic $<90$ & $35094(78.0)$ \\
\hline With hypertension and diabetes & $n=9782 \ddagger$ \\
\hline Systolic $<130$ & $5050(51.6)$ \\
\hline Diastolic $<80$ & $7350(75.1)$ \\
\hline Both systolic $<130$ and diastolic $<80$ & $4434(45.3)$ \\
\hline
\end{tabular}

*Among patients for whom blood pressure data were available. Achievement of targets was determined on the basis of the average of the last 3 measurements (or whatever was available) taken in the 2 years before the study.

†Data missing for 12199 (21.3\%) of the 57180 patients with hypertension.

fData missing for 2694 (21.6\%) of the 12476 patients with both hypertension and diabetes.

\section{Conclusion}

This report provides estimates of the prevalence, management approaches and blood pressure control in primary care practices in Canada based on CPCSSN data. Our analysis of CPCSSN data showed that $22.8 \%$ of patients in participating practices had hypertension and that most were able to control the condition with only 1 or 2 medications. Although achievement of blood pressure targets was high, patients with hypertension had more comorbidities and saw their primary care provider more often than those without hypertension. Our results are similar to the findings of community-based surveys, which indicates that CPCSSN data may provide a reasonable data source for monitoring the state of hypertension in Canada.

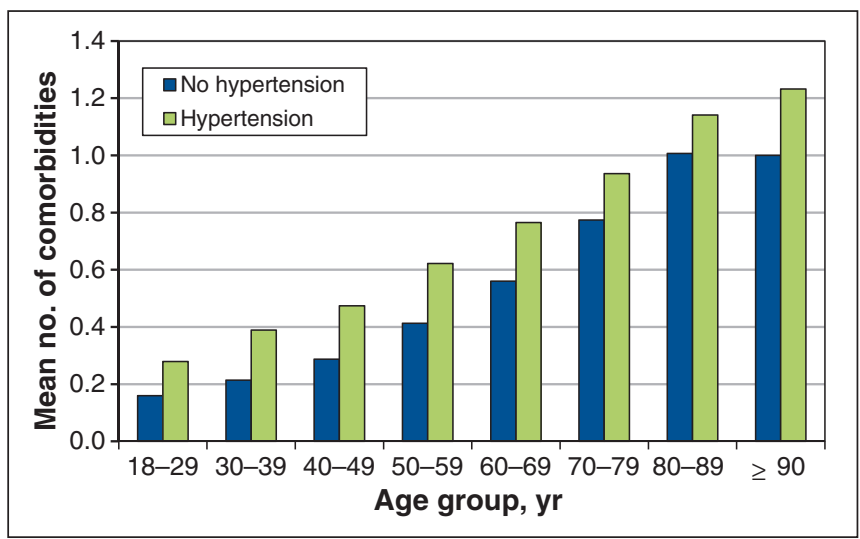

Figure 2: Mean number of comorbidities per patient, by age and hypertension status. Table 5: Age- and sex-adjusted prevalence ratios for
hypertension, by comorbid conditions*

\begin{tabular}{|c|c|c|c|c|}
\hline \multirow[b]{2}{*}{ Comorbidity } & \multicolumn{3}{|c|}{ No. of patients } & \multirow[b]{2}{*}{$\begin{array}{c}\text { Prevalence } \\
\text { ratio } \\
(95 \% \mathrm{Cl})\end{array}$} \\
\hline & $\begin{array}{c}\text { All } \\
n=250346\end{array}$ & $\begin{array}{c}\text { With } \\
\text { hypertension } \\
n=57180\end{array}$ & $\begin{array}{c}\text { Without } \\
\text { hypertension } \\
n=193166\end{array}$ & \\
\hline Diabetes & 25306 & 12476 & 12830 & $\begin{array}{c}1.69 \\
(1.65-1.73)\end{array}$ \\
\hline Depression & 40550 & 10682 & 29868 & $\begin{array}{c}1.24 \\
(1.22-1.27)\end{array}$ \\
\hline COPD & 10043 & 4865 & 5178 & $\begin{array}{c}1.22 \\
(1.17-1.26)\end{array}$ \\
\hline Osteoarthritis & 29813 & 14084 & 15729 & $\begin{array}{c}1.35 \\
(1.32-1.38)\end{array}$ \\
\hline Dementia & 5634 & 2740 & 2894 & $\begin{array}{c}0.96 \\
(0.91-1.01)\end{array}$ \\
\hline Epilepsy & 2512 & 607 & 1905 & $\begin{array}{c}1.05 \\
(0.94-1.16)\end{array}$ \\
\hline Parkinsonism & 958 & 473 & 485 & $\begin{array}{c}1.01 \\
(0.89-1.15)\end{array}$ \\
\hline
\end{tabular}

Note: $\mathrm{Cl}=$ confidence interval, $\mathrm{COPD}=$ chronic obstructive pulmonary disease *The probability of each comorbid condition was modelled, with hypertension (yes/no) as the predictor, along with age and sex. Example: Patients with hypertension were 1.69 times as likely to have diabetes as patients without hypertension. 


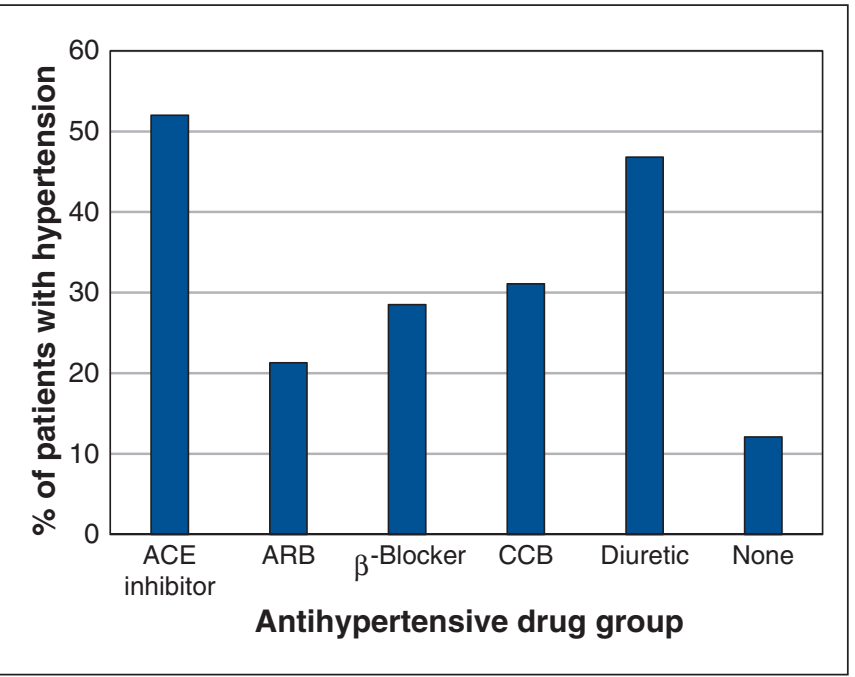

Figure 3: Distribution of antihypertensive medications prescribed. $\mathrm{ACE}=$ angiotensin-converting enzyme, $\mathrm{ARB}=$ angiotensin-receptor blocker, $\mathrm{CCB}=$ calcium-channel blocker.

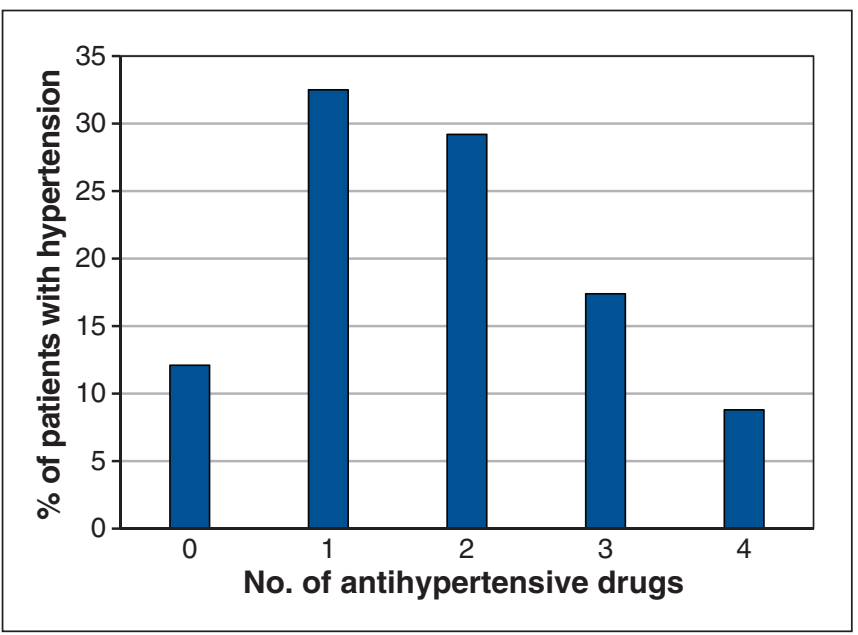

Figure 4: Number of antihypertensive drugs prescribed per patient.

\section{References}

1. Lim SS, Vos T, Flaxman AD, et al. A comparative risk assessment of burden of disease and injury attributable to 67 risk factors and risk factor clusters in 21 regions, 1990-2010: a systematic analysis for the Global Burden of Disease Study 2010. Lancet 2012;380:2224-60.

2. Mackay J, Mensah GA, Mendis S, et al. Atlas of heart disease and stroke. Geneva: World Health Organization; 2004.
3. World Health Organization. Global bealth risks: mortality and burden of disease attributable to selected major risks. Geneva: WHO Press; 2009.

4. WHO publishes definitive atlas on global heart disease and stroke epidemic Indian 7 Med Sci 2004;58:405-6.

5. Canadian Health Measures Survey (CHMS) 2009-2011: Blood pressure of Canadian adults. Ottawa: Statistics Canada. Cat. no. 82-625-X. Available: www.statcan .gc.ca/pub/82-625-x/2012001/article/11714-eng.htm (accessed 2015 Jan. 28).

6. Vasan RS, Beiser A, Seshadri S, et al. Residual lifetime risk for developing hypertension in middle-aged women and men. FAMA 2002;287:1003-10.

7. Hemmelgarn BR, Chen G, Walker R, et al. Trends in antihypertensive drug prescriptions and physician visits in Canada between 1996 and 2006. Can 7 Cardiol 2008;24:507-12

8. Joffres MR, Campbell NRC, Manns B, et al. Estimate of the benefits of a population-based reduction in dietary sodium additives on hypertension and its related health care costs in Canada. Can 7 Cardiol 2007;23:437-43.

9. Birtwhistle RV. Canadian Primary Care Sentinel Surveillance Network: a developing resource for family medicine and public health. Can Fam Physician 2011;57:1219-20.

10. Birtwhistle R, Keshavjee K, Lambert-Lanning A, et al. Building a pan-Canadian primary care sentinel surveillance network: initial development and moving forward. 7 Am Board Fam Med 2009;22:412-22.

11. Kadhim-Saleh A, Green M, Williamson T, et al. Validation of the diagnostic algorithms for 5 chronic conditions in the Canadian Primary Care Sentinel Surveillance Network (CPCSSN): a Kingston Practice-based Research Network (PBRN) report. 7 Am Board Fam Med 2013;26:159-67.

12. Williamson T, Green ME, Birtwhistle R, et al. Validating the 8 CPCSSN case definitions for chronic disease surveillance in a primary care database of electronic health records. Ann Fam Med 2014;12:367-72.

13. Delivery mode data technical specifications. Ottawa: Canada Post; 2014. Available: www.canadapost.ca/cpo/mr/assets/pdf/business/delmodetechspecs_en.pdf (accessed 2015 Jan. 28)

14. The Canadian population in 2011: age and sex. Ottawa: Statistics Canada; 2011 Available: www12.statcan.gc.ca/census-recensement/2011/as-sa/98-311-x/98 -311-x2011001-eng.pdf (accessed 2015 Jan. 28).

15. Population with a regular medical doctor, by age group and sex. Ottawa: Statistics Canada; 2014. Available: www.statcan.gc.ca/tables-tableaux/sum-som /101/cst01/health75a-eng.htm (accessed 2015 Jan. 28).

Affiliations: Department of Family Medicine (Godwin, Asghari), Memorial University, St. John's, NL; Departments of Family Medicine (Williamson, Khan, Morkem, Birtwhistle), and Public Health Sciences (Williamson, Birtwhistle), Queen's University, Kingston, Ont.; Department of Family and Emergency Medicine (Kaczorowski), Université de Montréal and Centre de recherche du Centre hospitalier de l'Université de Montréal, Montréal, Que.; Department of Family Practice (Dawes), University of British Columbia, Vancouver, BC

Contributors: All of the authors contributed to the concept and design of the study. Tyler Williamson and Shahriar Khan were primarily responsible for the data analysis. Marshall Godwin drafted the manuscript, and all of the coauthors contributed substantial revisions and intellectual content. All of the authors approved the final version submitted for publication and agreed to act as guarantors of the work.

Funding: Funding for this publication was provided by the Public Health Agency of Canada. The views expressed herein do not necessarily represent the views of the agency.

Supplemental information: For reviewer comments and the original submission of this manuscript, please see www.cmajopen.ca/content/3/1/ E76/suppl/DC1 